\title{
Validity of free testosterone calculation in pregnant women
}

\author{
M P Schuijt ${ }^{1,2}$, C G J Sweep ${ }^{2}$, R van der Steen ${ }^{2}$, A J Olthaar ${ }^{2}$, N M M L Stikkelbroeck ${ }^{3}$, H A Ross ${ }^{2}$ and \\ A E van Herwaarden ${ }^{2}$ \\ 'Department of Laboratory Medicine, Slingeland Hospital, Doetinchem, The Netherlands \\ 2Department of Laboratory Medicine, Radboud University Medical Centre, Nijmegen, The Netherlands \\ ${ }^{3}$ Division of Endocrinology, Department of Internal Medicine, Radboud University Medical Centre, Nijmegen, The Netherlands
}

Correspondence should be addressed to A E van Herwaarden: Teun.vanHerwaarden@radboudumc.nl

\begin{abstract}
Objective: Increased maternal testosterone concentration during pregnancy may affect the fetus. Therefore it is clinically relevant to have a quick and reliable method to determine free testosterone levels. Current calculators for free testosterone are suspected to perform poorly during pregnancy due to suggested competition between high levels of estradiol and free (bio-active) testosterone for sex hormone-binding globulin (SHBG) binding. Therefore, it is claimed that reliable calculation of free testosterone concentration is not possible. However, recent evidence on SHBG-binding sites questions the estradiol effect on the testosterone-SHBG binding during pregnancy. In this study, we investigated whether the free testosterone concentration can be calculated in pregnant women.

Design and methods: Free testosterone was measured with a specially developed equilibrium dialysis method combined with liquid chromatography tandem mass spectrometry (LC-MS/MS). Free testosterone was also calculated with the formulas of Vermeulen et al. and Ross et al.

Results: Total and free testosterone measured in healthy men and women were in good agreement with earlier reports. In pregnant women, total testosterone values were higher than in non-pregnant women, whereas free testosterone values were comparable. Calculated free testosterone levels in pregnant women were highly correlated, but marginally higher, compared to measured free testosterone levels. Conclusions: We developed an equilibrium dialysis-LC-MS/MS method for the measurement of free testosterone in the low range of pregnant and non-pregnant women. Although during pregnancy total testosterone is increased, this is not the case for free testosterone. The free testosterone formulas perform well in pregnant women.
\end{abstract}

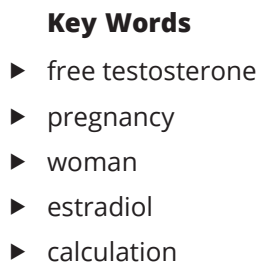

Endocrine Connections (2019) 8, 672-679

\section{Introduction}

In women, small amounts of testosterone are synthesized in the ovaries (1). Next to the gonads, testosterone is also produced and secreted from the adrenal glands in both sexes. Most testosterone circulates tightly bound to sex hormone-binding globulin (SHBG) or weakly bound to albumin, orosomucoid and corticosteroid-binding globulin (2). Only $1-4 \%$ circulates as free testosterone, which is considered to be the biologically active component $(2,3)$. Determination of free testosterone levels is important in the diagnosis of androgen deficiency in men (4) and androgen excess in women (i.e., polycystic ovary syndrome and hirsutism $(5,6))$. During pregnancy increased maternal testosterone is associated with fetal growth restriction in utero $(7,8)$, it may perturb the 
insulin-glucose homeostasis (9) and possibly leads to fetal virilization $(10,11)$.

Direct measurements of free testosterone by immunoassays have shown to give unreliable results (12, $13,14)$ and accurate measurements can only be performed with methods such as equilibrium dialysis, symmetric dialysis or ultrafiltration (3).

We developed a measurement method for free testosterone with equilibrium dialysis followed by liquid chromatography tandem mass spectrometry (ED-LC-MS/MS). LC-MS/MS enables the accurate, specific and matrix-independent measurement of testosterone with direct calibration. Equilibrium dialysis enables to separate the free- from protein-bound testosterone with minimal disturbance of the physiological equilibrium when performed under adequate conditions and may be suitable as the reference measurement procedure (2).

For daily routine use, however, ED-LC-MS/MS is inconvenient. Therefore formulas for calculating free testosterone from total testosterone and concentrations of its binding proteins SHBG and albumin concentrations have been developed which make quantification of free testosterone concentration easily accessible. The formulas that are based on law of mass action perform well in men and, even at low free testosterone concentrations, in women $(12,13)$.

In pregnancy, elevated maternal testosterone levels may affect the fetus. Therefore, it is important to have a reliable and quick method to determine free testosterone levels. The possible use of free testosterone calculation during pregnancy, when estradiol concentration is substantially increased, is debated as SHBG is also able to bind estradiol with similar binding affinity (3-4 times less than testosterone) $(2,13,15,16)$. Recently, evidence is found for differential binding of androgens and estrogens to SHBG (16) and dynamic regulation of the homodimeric SHBG-binding sites $(2,17,18)$. In their review Goldman et al. (2) elegantly describe that the testosterone binding to SHBG is much better represented by a multistep dynamic model of allosteric regulation instead of the linear model used by Vermeulen et al. (13), Sodergard et al. (19) and Maher et al. (20). Since the assumed estradiol interference on the testosterone binding to SHBG utilizes the linear model, these new insights question this assumed estradiol interference.

To investigate this, free testosterone levels were measured with the state of the art method ED-LC-MS/MS in pregnant and in non-pregnant females to investigate whether the free testosterone concentration is different between these groups. Furthermore, total testosterone,
SHBG and estradiol were measured in these groups to calculate free testosterone by the formula of Vermeulen et al. (13) and by Ross et al. (21) and to investigate whether or not calculation of free testosterone yields results differing from those obtained by ED-LC-MS/MS. This will answer the question whether free testosterone calculation may be used in pregnant females.

\section{Materials and methods}

\section{Subjects}

Serum samples for quantification of total and free testosterone concentration in pregnant women were derived from surplus anonymized material from women aged between 19 and 38 years attending the Slingeland Hospital (a large regional hospital) laboratory for the routine national antenatal screening. These included 65 random samples taken in the first trimester (week 8 till 13) and 37 random samples taken at the end of the second trimester (week 27 till week $28+6$ days) from different pregnant women. For comparison total and free testosterone was determined using surplus anonymized random serum from 46 non-pregnant women (aged 14-79 years) and for method validation purposes from 47 men (age 14-81 years). These patients were referred to the same hospital laboratory by general practitioners for screening for allergy and/or auto-immune disease. All samples were stored at $-20^{\circ} \mathrm{C}$ before measurement. Consent has been obtained from each patient or subject after full explanation of the purpose and nature of all procedures used. The study was approved by Ethics Committee of the Radboud University Nijmegen Medical Centre.

\section{Materials}

\section{Measurement of free testosterone by equilibrium dialysis - LC-MS/MS}

Equilibrium dialysis Serum was dialyzed in a multi-cell equilibrium dialyzer using Teflon dialyzing cells consisting of two identical parts between which a flat membrane is fitted (Dianorm-Geräte, Munic, Germany). The dialysis cells are incubated in a water bath with constant agitation by a rotating apparatus and temperature during dialysis was maintained at $37 \pm 0.5^{\circ} \mathrm{C}$, by constant monitoring with an immersion thermostatic system (Tinytag TGP-4020 logger and PB5001-1M5 sonde; Gemini data loggers). The dialysis membranes were prepared from Dianorm (Diachema dialysis membranes 10.14) with a

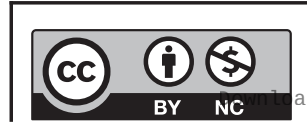

This work is licensed under a Creative Commons Attribution-NonCommercial 4.0 International License. ded from Bioscientifica.com at 04/26/2023 12:51:27PM 
cut-off of $5 \mathrm{kDa}$. Equilibrium dialysis was performed for $5 \mathrm{~h}$ with $1 \mathrm{~mL}$ serum against $1 \mathrm{~mL}$ HEPES buffer, while rotating the dialysis apparatus at $20 \mathrm{rpm}$.

The HEPES buffer used for equilibrium dialysis was composed to reflect the electrolyte composition and $\mathrm{pH}$ of serum and contained in addition to $12.570 \mathrm{~g} / \mathrm{L}$ $\mathrm{N}$-(2-hydroxyethyl)piperazine-N'-(2-ethanesulfonic acid (HEPES), $5.353 \mathrm{~g} / \mathrm{L} \mathrm{NaCl}, 0.200 \mathrm{~g} / \mathrm{L} \mathrm{KCl}, 0.224 \mathrm{~g} / \mathrm{L}$ $\mathrm{KH}_{2} \mathrm{PO}_{4}, 0.275 \mathrm{~g} / \mathrm{L} \quad \mathrm{MgSO}_{4} \cdot 7 \mathrm{H}_{2} \mathrm{O}, 0.300 \mathrm{~g} / \mathrm{L}$ urea, 0.275 $\mathrm{g} / \mathrm{L} \mathrm{CaCl}_{2} \cdot 2 \mathrm{H}_{2} \mathrm{O}, 0.900 \mathrm{~g} / \mathrm{L} \mathrm{NaOH}$, and $0.520 \mathrm{~g} / \mathrm{L} \mathrm{NaN} \mathrm{N}_{3}$ (all from Merck). $\mathrm{pH}$ was adjusted with $\mathrm{HCl}$ to $\mathrm{pH} 7.40$ (at $37^{\circ} \mathrm{C}$ ) $(22)$. The buffer was diluted by ultrapure water produced with a Milli Advantage A10. The quality of the other solvents was gradient grade (methanol, 2-propanol, formic acid; Biosolve and ammonium hydroxide (28-30 wt \%); Across).

To ensure a physiological $\mathrm{pH}$ of $7.40 \pm 0.03$ in the serum sample at $37.0^{\circ} \mathrm{C}, 100 \mu \mathrm{L}$ of a concentrated HEPES buffer $(8.8 \mathrm{~g} / \mathrm{L} \mathrm{NaOH}$, HEPES and $\mathrm{pH}$ adjusted with $\mathrm{HCl}$ to $\mathrm{pH} 7.40\left(\right.$ at $\left.37^{\circ} \mathrm{C}\right)$ ) was added to the serum sample before dialysis. Experiments were performed to determine the influence of $\mathrm{pH}$ and temperature (22).

LC-MS/MS with solid phase extraction Testosterone in dialysate was analyzed by LC-MS/MS after solid phase extraction. An eight-point calibration series with testosterone $(0.03-69 \mathrm{nmol} / \mathrm{L})$ (Steraloids, purity $>99 \%)$ was prepared, aliquoted $\left(100 \mu \mathrm{L}\right.$ each) and stored at $-40^{\circ} \mathrm{C}$ until analysis. In every run one aliquot per calibration point was used.

Internal standard $(5 \mathrm{nmol} / \mathrm{L})$ was added $\left[{ }^{13} \mathrm{C}_{3}\right]$ Testosterone (Isoscience, King of Prussia, PA; purity $>98 \%)$ to $500 \mu \mathrm{L}$ dialysate with subsequent solid phase extraction using Oasis MCX 1cc cartridges (Waters Corp). Columns were pre-equilibrated with $1 \mathrm{~mL}$ methanol:isopropanol (95:5) and subsequently washed with $1 \mathrm{~mL} \mathrm{H}_{2} \mathrm{O}$. After application of $500 \mu \mathrm{L}$ of the sample, columns were washed with $1 \mathrm{~mL} \mathrm{H}_{2} \mathrm{O}: \mathrm{NH}_{4} \mathrm{OH}$ (95:5) and $1 \mathrm{~mL}$ methanol: $\mathrm{H}_{2} \mathrm{O}$ :formic acid (20:78:2). The $300 \mu \mathrm{L}$ eluate (methanol) was dried under a stream of $\mathrm{N}_{2}$ gas, reconstituted in $100 \mu \mathrm{L}$ of methanol: $\mathrm{H}_{2} \mathrm{O}$ (30:70), thereby being concentrated five times. Of this $100 \mu \mathrm{L}$ reconstituted sample $10 \mu \mathrm{L}$ was injected and also per calibration point $10 \mu \mathrm{L}$ from each aliquot was injected into an Agilent Technologies 1290 Infinity VL UHPLCsystem (Agilent Technologies) equipped with a BEH C18 $(1.7 \mu \mathrm{m} 2.1 \times 50 \mathrm{~mm})$ analytical column (Waters Corp.) at $60^{\circ} \mathrm{C}$. Mobile phase A (methanol:water $20: 80+2 \mathrm{mmol} / \mathrm{L}$ $\mathrm{NH}_{4} \mathrm{CH}_{3} \mathrm{COO}+0.1 \%$ formic acid) and $\mathrm{B}$ (methanol:water
$98: 2+2 \mathrm{mM} \mathrm{NH}_{4} \mathrm{CH}_{3} \mathrm{COO}+0.1 \%$ formic acid) were run in a gradient $(0.4 \mathrm{~mL} / \mathrm{min})$. The gradient program was as follows: start gradient 70:30 A:B for $2.5 \mathrm{~min}$; then to 60:40 A:B in $2 \mathrm{~min}$; followed by a gradient in $2.5 \mathrm{~min}$ to $35: 65$ and a subsequent gradient in $0.5 \mathrm{~min}$ to $2: 98$ to remain such for $0.5 \mathrm{~min}$ and thereafter to $70: 30 \mathrm{~A}: \mathrm{B}$ in $0.5 \mathrm{~min}$ and remain such for $0.5 \mathrm{~min}$. Retention time was $4.3 \mathrm{~min}$ with a total run time of $9 \mathrm{~min}$. An Agilent 6490 tandem mass spectrometer (Agilent Technologies) was operated in the electrospray positive ion mode, with a capillary voltage $3.5 \mathrm{kV}$, fragmentor voltage $380 \mathrm{~V}$, sheath gas temperature $350^{\circ} \mathrm{C}$ and gas temperature $150^{\circ} \mathrm{C}$ with $\mathrm{N}_{2}$ collision gas. The collision energy was optimized for all analytes. Two mass transitions were monitored for each analyte, and the internal standards. The first transition was used for quantification, the second for confirmation. The transitions (Q1>Q3), collision energy (between brackets) and dwell time were $\mathrm{m} / \mathrm{z} 289>97(30 \mathrm{eV})$ and $\mathrm{m} / \mathrm{z} 289>109(30 \mathrm{eV})$ for TES $(50 \mathrm{~ms}) ; \mathrm{m} / \mathrm{z} 292>100$ $(30 \mathrm{eV})$ and $\mathrm{m} / \mathrm{z} 292>112(30 \mathrm{eV})$ for $\left[{ }^{13} \mathrm{C}_{3}\right]$-TES $(50 \mathrm{~ms})$.

Validation experiments The correlation coefficient $(r)$ of each calibration curve had to be $>0.995$ and the signalto-noise ratio $>10$. Samples with known concentrations were measured in each run as internal quality controls.

Ion suppression was assessed by continuous infusion of the labeled steroid in a dialysate matrix. The abundance was compared between a dialysate matrix and mobile phase at the retention time of testosterone.

Total imprecision was assessed by an adapted CLSI EP5 protocol with pooled samples of free testosterone at three levels. Samples were dialyzed and measured by LC-MS/MS in duplicate in independent experiments $(n=10)$. Experiments were performed to investigate the lower limit of quantification (LOQ). The LOQ was defined as the free testosterone concentration with a total coefficient of variation $(\mathrm{CV})$ of $10 \%$, determined by repeated serum measurements of free testosterone in independent experiments and calculated by EP Evaluator. For the statistical processing of data, measurements below the LOQ were quantified when they had a signal to noise ratio of $>10$. Measurements with a signal to noise ratio $<10$ were quantified for statistical processing as $0,5^{*} \mathrm{LOQ}$.

Recovery of testosterone was calculated from an addition experiment in dialysate (addition of 75, 100 and $200 \mathrm{pmol} / \mathrm{L}$ from NIST SRM971). Method comparison was conducted with a validated symmetric dialysis LC-MS/MS method.
This work is licensed under a Creative Commons Attribution-NonCommercial 4.0 International License. ded from Bioscientifica.com at 04/26/2023 12:51:27PM via free access 


\section{Measurement of free testosterone by symmetric dialysis - LC-MS/MS}

Free testosterone in serum was measured by symmetric dialysis (which, as an indirect method, yields the free fraction or percent free testosterone) coupled to total testosterone measurement as described elsewhere (23). The symmetric dialysis method correlated well (0.97) with the candidate reference measurement procedure of free testosterone (24) and measurements in healthy males yielded free testosterone results in the range 120 - $750 \mathrm{pmol} / \mathrm{L}$ (24). In this report, the symmetric dialysis results were coupled to total testosterone measurements by LC-MS/MS, the latter being described elsewhere (25).

\section{Measurement of total testosterone, SHBG, albumin and estradiol}

SHBG and estradiol (3rd gen) were measured using a Roche Cobas8000 (E801) random access analyzer (Roche Diagnostics) and albumin were measured using a Roche Cobas8000 (C702) random access analyzer using the bromocresol purple method. Reference values for SHBG (non-pregnant) females: $32-128 \mathrm{nmol} / \mathrm{L}$, for albumin: $43-55 \mathrm{~g} / \mathrm{L}$ and for estradiol (ovulatory phase) females: $151-1460 \mathrm{pmol} / \mathrm{L}$. Intra-assay imprecision was $2.3 \%$ at $10.9 \mathrm{nmol} / \mathrm{L}$ and $2.5 \%$ at $37.5 \mathrm{nmol} / \mathrm{L}$ for $\mathrm{SHBG}, 3.8 \%$ at $170 \mathrm{pmol} / \mathrm{L}$ and $1.1 \%$ at $1190 \mathrm{pmol} / \mathrm{L}$ for estradiol, $1.2 \%$ at $25 \mathrm{~g} / \mathrm{L}$ for albumin, respectively. Total testosterone in serum was analyzed by LC-MS/MS after solid phase extraction as described by Ter Horst et al. (25)

\section{Calculation of free testosterone}

Free testosterone was calculated, based on total testosterone, SHBG and albumin with the formula as reported by Vermeulen et al. (13) and the formula as reported by Ross et al. (21). In the non-pregnant situation the variation in serum albumin is considered negligible (13) and therefore a fixed albumin concentration of $43 \mathrm{~g} / \mathrm{L}$ is generally used in these formulas. Since pregnant women have low albumin levels $(20,26)$, the calculations were performed with the actual albumin levels. To investigate the influence of albumin in the formulas during pregnancy, calculations were also performed with a fixed albumin concentration of $43 \mathrm{~g} / \mathrm{l}$.

\section{Statistical analysis}

EP Evaluator (David G. Rhoads Associates Inc. Consultants, South Burlington, VT, USA; release 12) and Excel 2007 (Microsoft, Redmond, WA, USA) were used to analyze the data.

\section{Results}

\section{Dialysis}

The effect of $\mathrm{pH}$ and temperature on free testosterone was investigated in pool sera with concentrations of approximately 80 and $350 \mathrm{pmol} / \mathrm{L} \quad(n=4)$ of free testosterone. $\mathrm{pH}$ was investigated at 7.30, 7.40 and 7.50 (at $37^{\circ} \mathrm{C}$ ) and the temperature was investigated at 35.0, 37.0 and $39.0^{\circ} \mathrm{C}$. Free testosterone maximum increase was $3.4 \%$ (at $\mathrm{pH} 7.30$ ) and $-3.5 \%$ (at $\mathrm{pH} 7.50$ ) compared to a $\mathrm{pH}$ of 7.40 . At $35.0^{\circ} \mathrm{C}$ the free testosterone concentrations decreased maximally by $10.7 \%$ and at $39.0^{\circ} \mathrm{C}$ the concentrations of free testosterone maximally increased by $15.2 \%$ compared to dialysis at $37.0^{\circ} \mathrm{C}$ indicating the necessity for accurate temperature during dialysis.

\section{LC-MS/MS}

To determine the total imprecision of the free testosterone measurement, free testosterone was measured in pool sera by ED-LC-MS/MS. At 9, 57 and $254 \mathrm{pmol} / \mathrm{L}$ the coefficients of variance were subsequently $7.9,3.4$ and $4.0 \%$. The LOQ (CV: $10 \%)$ was determined at $6 \mathrm{pmol} / \mathrm{L}$. Samples with deviations larger than $10 \%$, however, with signal-to-noise ratios $>10$, were quantified according to the calibrators for proper statistical processing of data, an example is shown in Fig. 1. To investigate the matrix effect of dialysated samples after solid phase extraction, ion suppression experiments were performed. At a steady infusion of testosterone into the MS/MS, three different matrix samples after solid phase extraction were injected. The ion suppression by the matrix was between 2.9 and $11.8 \%$.

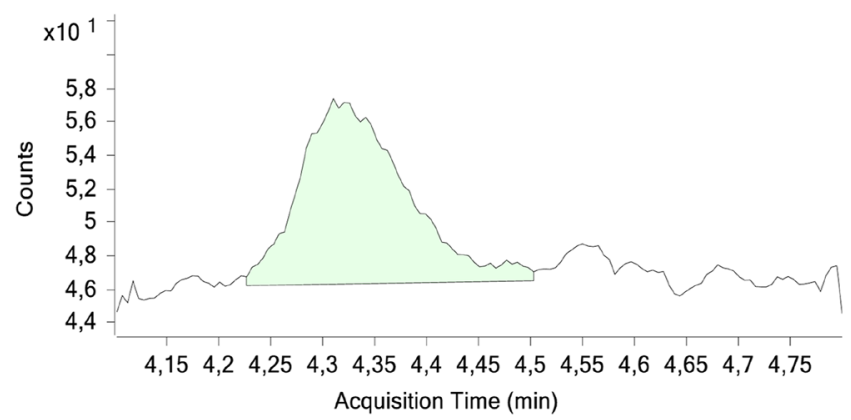

Figure 1

Chromatogram of free testosterone in a sample of $1 \mathrm{pmol} / \mathrm{L}$ (i.e. LC-MS/MS measurement in a concentrated solid phase extracted dialysate of $5 \mathrm{pmol} / \mathrm{L}$ ). 
A method comparison with sera from adult males and adult females with a validated symmetric dialysis LC-MS/MS method yielded a slope of 1.01 (0.94-1.07); an intercept of -0.92 ( -4.7 to 2.8 ) pmol/L and a correlation coefficient of 0.99 in a range of $1-300 \mathrm{pmol} / \mathrm{L}(n=56)$. The accuracy of the LC-MS/MS method was 96, 94 and 95\% at $79 \mathrm{pmol} / \mathrm{L}, 114 \mathrm{pmol} / \mathrm{L}$ and $225 \mathrm{pmol} / \mathrm{L}$, respectively.

\section{Total and free testosterone measurements}

In (non-pregnant) women total testosterone did not exceed $1.6 \mathrm{nmol} / \mathrm{L}$, consistent with our laboratory reference values (adult females $0.5-2.0 \mathrm{nmol} / \mathrm{L}$ ) and measured free testosterone did not exceed $22 \mathrm{pmol} / \mathrm{L}$. In men total testosterone was between 2.2 and $30.5 \mathrm{nmol} / \mathrm{L}$, consistent with our laboratory reference values $(10.5-37.0 \mathrm{nmol} / \mathrm{L}$ (25)) and free testosterone was measured between 67 and $454 \mathrm{pmol} / \mathrm{L}$ (Fig. 2) in agreement with other reports $(4,27,28,29)$. As described by others (30) free testosterone concentration declined with age in men. No age-related decline in free testosterone levels was observed in women, nor a difference between pre- and post-menopausal females. Estradiol concentration was highly increased in pregnant women, up to $90,000 \mathrm{pmol} / \mathrm{L}$ compared to nonpregnant females. Although in pregnant women the total testosterone concentration (mean: $2.1 \mathrm{nmol} / \mathrm{L}$; range: $0.6-9.0 \mathrm{nmol} / \mathrm{L}$ ) was higher compared to non-pregnant women (mean: $0.6 \mathrm{nmol} / \mathrm{L}$; range: $0.0-1.6 \mathrm{nmol} / \mathrm{L}$; $P<0.0001)$, this was not observed for the free testosterone concentration (Fig. 3). On the contrary, the mean free testosterone concentration in pregnant women was even somewhat lower than that in non-pregnant women (4 vs $6 \mathrm{pmol} / \mathrm{L}$, respectively, $P<0.002)$; however, values were in the same range ( $0-19$ vs $0-22 \mathrm{pmol} / \mathrm{L}$, respectively). The higher concentration of total testosterone in pregnant women was not related to the elevated SHBG concentration in pregnant women $(r=0.31$; range: $91-650 \mathrm{nmol} / \mathrm{L})$.

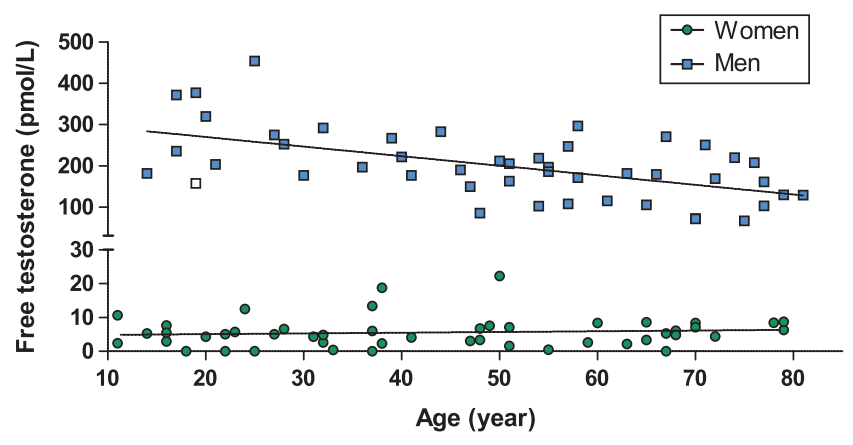

Figure 2

Free testosterone levels in men and women at different ages.

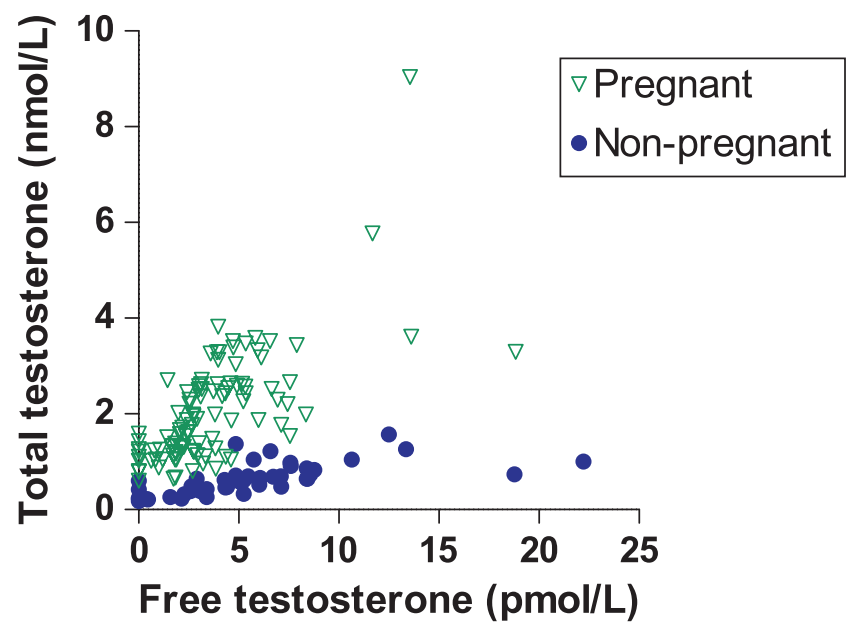

Figure 3

Total testosterone and free testosterone levels in pregnant women (12 and 27 weeks of gestation) and non-pregnant women.

\section{Comparison of calculated versus measured free testosterone levels in pregnant women}

Free testosterone was calculated from total testosterone and SHBG measurements by the formula of Vermeulen et al. (13) or Ross et al. (21).

Calculated free testosterone levels in pregnant women were well correlated, but marginally higher, compared to measured free testosterone levels with ED-LC-MS/MS (formula of Vermeulen et al.: intercept of $2.4 \mathrm{pmol} / \mathrm{L}$ and slope of 1.06; $r=0.89$ and formula of Ross et al. intercept of $2.1 \mathrm{pmol} / \mathrm{L}$ and slope of $0.91 ; r=0.89$, respectively). Average measured or calculated free testosterone levels did not differ in women being 12 or 27 weeks pregnant. As shown in Fig. 4, estradiol levels did increase to almost $90,000 \mathrm{pmol} / \mathrm{L}$ in serum of women being 27 weeks pregnant, but it did not significantly influence the calculations nor the measurements of free testosterone levels. Also, no correlation was found between estradiol levels and the ratio free testosterone(calculated)/free testosterone(measured). With the approach as described in Ross et al. (21) estimates of the testosterone-SHBG equilibrium constants (Kd) and the albumin binding avidity were made. This estimated $\mathrm{Kd}$ of testosterone for SHBG did not differ significantly from the values used in the calculations. In contrast, the calculations tended to underestimate the effect of binding to other binding sites, possibly not only albumin.

The decreased albumin value in the pregnant women (mean: $32 \mathrm{~g} / \mathrm{L}$ ) was in agreement with earlier reports $(20,26)$. It only marginally influenced the calculations of free testosterone. The mean decrease of calculated

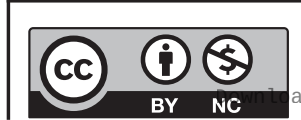

This work is licensed under a Creative Commons Attribution-NonCommercial 4.0 International License. ded from Bioscientifica.com at 04/26/2023 12:51:27PM via free access 


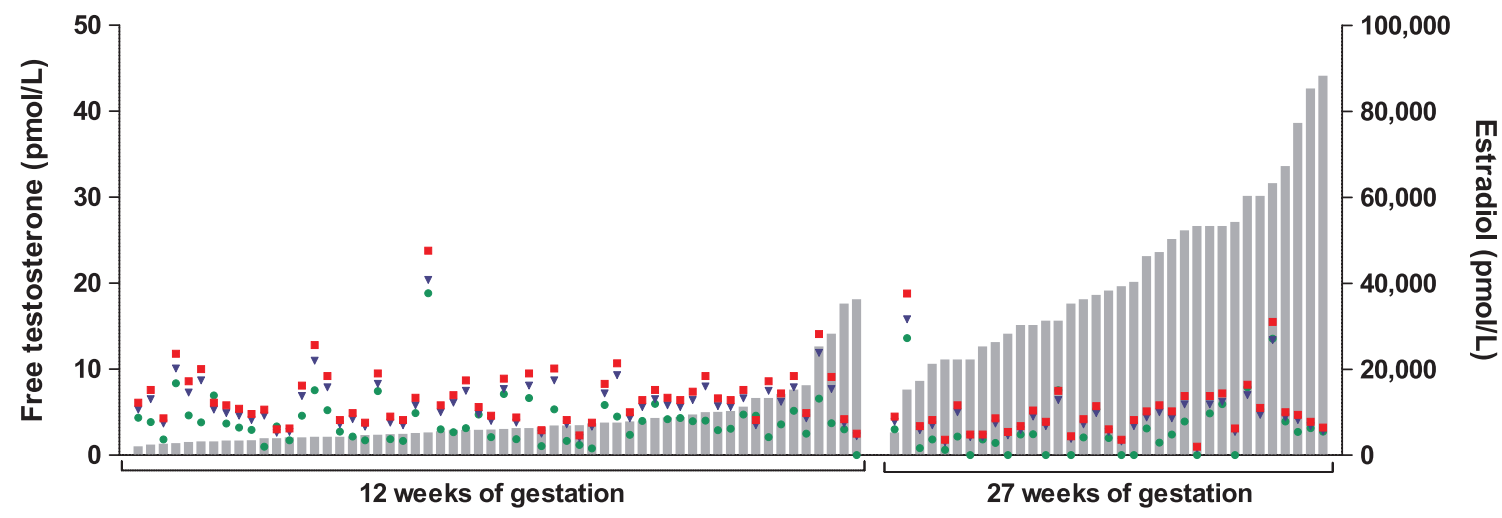

\section{Figure 4}

Free testosterone and estradiol levels in women at 12 and 27 weeks of gestation, arranged per individual in order of increasing estradiol. Free testosterone levels are measured with ED-LCMS/MS (green), calculated with the free testosterone formula of Ross et al. (blue) and the formula of Vermeulen et al. (red). Estradiol levels are shown as gray bars.

free testosterone in pregnant females with the formula of Ross et al. (21) was $-0.01 \pm 0.01 \%$ (mean \pm s.D.), whereas with the formula of Vermeulen et al. (13) it was $-1.7 \pm 0.9 \%$ when a fixed albumin concentration of $43 \mathrm{~g} / \mathrm{L}$ was used instead of the measured albumin.

\section{Discussion}

Increased maternal testosterone concentration during pregnancy may lead to fetal growth restriction in utero (7, 8), disturbance of the insulin-glucose homeostasis (9) and possible fetal virilization $(10,11)$. Therefore it is clinically relevant to have a quick and reliable method to determine the active (free) testosterone levels. Since measurements of free testosterone can only be accurately performed with inconvenient dialysis or ultrafiltration techniques to separate free from bound hormone (3), formulas reported by Vermeulen et al. (13) and Ross et al. (21) are broadly used because they make free testosterone quantification readily accessible.

However, one has been reluctant to use these formulas in premenopausal and especially pregnant women due to assumed influence of the increased estradiol on the testosterone-binding sites of SHBG as reported by Vermeulen et al. (13). The equilibrium between free testosterone concentration, total available proteinbinding sites and total testosterone concentration is dependent upon the affinity of testosterone for its binding proteins expressed as the dissociation constant $\mathrm{Kd}$.

This estimated $\mathrm{Kd}$ is used in the calculation formulas to yield a result when total testosterone and SHBG concentration are available. The binding affinity of estradiol to SHBG is only 3-4 times lower than that of testosterone $(15,16)$ and it has been proposed that testosterone and estradiol compete for the SHBG-binding sites. Competition of elevated estradiol with testosterone for SHBG-binding sites has the same effect as lowering its affinity for testosterone (21). Up to now it is assumed that in pregnant women the increased estradiol concentration gives falsely low calculated free testosterone results, as the formulas do not account for this supposed apparent decrease in affinity of SHBG for testosterone. Moreover, as the calculations fully depend upon the accuracy of total testosterone and SHBG estimations, it has been advised against using these in women because of well-known inaccuracies in total testosterone estimates especially by direct immunoassay (21).

If, as recently reported $(2,16,17,18)$ the fraction of available SHBG-binding sites (available SHBG-binding sites/total SHBG-binding sites) changes when estradiol concentration (and SHBG itself) increases and/or estradiol binds differently to SHBG than free testosterone, this would have an effect on the assumed competitive relationship between testosterone and estradiol for SHBG.

We found (marginally) higher calculated free testosterone levels, which fully contrasts with the concept of falsely low free testosterone calculations in pregnant women due to estradiol competition. Moreover no significant difference in the affinity of SHBG for testosterone could be demonstrated not even at high levels of estradiol.

Although measurements with ED-LC-MS/MS better approximate the true value of free testosterone, calculated free testosterone in pregnant women with either formula seems well suitable in clinical practice. The (marginal)
This work is licensed under a Creative Commons Attribution-NonCommercial 4.0 International License. ded from Bioscientifica.com at 04/26/2023 12:51:27PM via free access 
overestimation of free testosterone by calculation is possibly due to a (small) underestimation of albumin or other binding proteins in these calculations.

Free testosterone was measured in this study by ED-LC-MS/MS. Equilibrium dialysis, and possibly ultrafiltration, is considered nowadays the state of the art measurement method with potentially minimal chance of disturbing the physiological equilibrium with unwanted shifts of testosterone from free to bound and vice versa. LC-MS/MS enables the direct measurement of testosterone concentration. The combination of these two techniques enables the accurate quantification of free testosterone. Importantly, the equilibrium dialysis should be performed under circumstances that minimally disturb the physiological equilibrium. For this reason, the dialysis is performed under $37.0^{\circ} \mathrm{C}$, at a $\mathrm{pH}$ of 7.4 and with a dialysis buffer that mimics the electrolyte composition of serum (22). In agreement with earlier reports that temperature of the dialysis should be strictly controlled (13), we demonstrate that temperature does influence the free testosterone concentration significantly. $\mathrm{pH}$ of the buffer also influences testosterone binding to SHBG; however, in the present study, this effect appeared to be marginal.

Although albumin levels are decreased during pregnancy, this did not have a large influence on the calculated free testosterone concentration. Since the free testosterone formulas mathematically describe the testosterone (non)-binding to SHBG and albumin, with increasing SHBG concentration the importance of albumin as binding protein diminishes in these formulas. And therefore, also changes in the albumin concentration are of less importance.

The ranges of total and free testosterone found in men and women are corresponding with earlier reports of measurements with LC-MS/MS $(27,28,29)$. As shown in Fig. 3 total testosterone is clearly increased during pregnancy compared to non-pregnant women and reaches levels in the range of male values, while free testosterone does not rise and stays in the range of non-pregnant women. In our cohort, total testosterone in pregnant women even exceeded the value used to diagnose steroid cell ovarian tumor in women ( $>7 \mathrm{nmol} / \mathrm{l})$ (31). This underlines the fact that free and not total testosterone should be used in (pregnant) women to investigate hyperandrogenism (6) or rare steroid cell ovarian tumors. Furthermore, it is in full agreement with the clinical findings that during a normal pregnancy no physiological androgen effects are observed in women.

In conclusion, calculations made with either the free testosterone formulas of Ross et al. (21) or
Vermeulen et al. (13) perform well in pregnant women. Calculations of free testosterone in women are not affected by estradiol. Moreover, free testosterone and not total testosterone should be used to investigate hyperandrogenism in pregnant women.

\section{Declaration of interest}

The authors declare that there is no conflict of interest that could be perceived as prejudicing the impartiality of the research reported.

\section{Funding}

This research did not receive any specific grant from any funding agency in the public, commercial or not-for-profit sector.

\section{References}

1 Lizneva D, Gavrilova-Jordan L, Walker W \& Azziz R. Androgen excess: investigations and management. Best Practice and Research: Clinical Obstetrics and Gynaecology 201637 98-118. (https://doi. org/10.1016/j.bpobgyn.2016.05.003)

2 Goldman AL, Bhasin S, Wu FCW, Krishna M, Matsumoto AM \& Jasuja R. A reappraisal of testosterone's binding in circulation: physiological and clinical implications. Endocrine Reviews 201738 302-324. (https://doi.org/10.1210/er.2017-00025)

3 Handelsman DJ \& Wartofsky L. Requirement for mass spectrometry sex steroid assays in the Journal of Clinical Endocrinology and Metabolism. Journal of Clinical Endocrinology and Metabolism 201398 3971-3973. (https://doi.org/10.1210/jc.2013-3375)

4 Bhasin S, Cunningham GR, Hayes FJ, Matsumoto AM, Snyder PJ, Swerdloff RS, Montori VM \& Task Force, Endocrine Society. Testosterone therapy in men with androgen deficiency syndromes: an Endocrine Society clinical practice guideline. Journal of Clinical Endocrinology and Metabolism 201095 2536-2559. (https://doi. org/10.1210/jc.2009-2354)

5 Stener-Victorin E, Holm G, Labrie F, Nilsson L, Janson PO \& Ohlsson C. Are there any sensitive and specific sex steroid markers for polycystic ovary syndrome? Journal of Clinical Endocrinology and Metabolism 201095 810-819. (https://doi.org/10.1210/jc.2009-1908)

6 Tosi F, Fiers T, Kaufman JM, Dall'Alda M, Moretta R, Giagulli VA, Bonara E \& Moghetti P. Implications of androgen assay accuracy in the phenotyping of women with polycystic ovary syndrome. Journal of Clinical Endocrinology and Metabolism 2016101 610-618. (https:// doi.org/10.1210/jc.2015-2807)

7 Carlsen SM, Jacobsen G \& Romundstad P. Maternal testosterone levels during pregnancy are associated with offspring size at birth. European Journal of Endocrinology 2006155 365-370. (https://doi. org/10.1530/eje.1.02200)

8 Smith AS, Birnie AK \& French JA. Maternal androgen levels during pregnancy are associated with early-life growth in Geoffroy's marmosets, Callithrix geoffroyi. General and Comparative Endocrinology 2010166 307-313. (https://doi.org/10.1016/j. ygcen.2009.10.008)

9 Eisner JR, Dumesic DA, Kemnitz JW \& Abbott DH. Timing of prenatal androgen excess determines differential impairment in insulin secretion and action in adult female rhesus monkeys. Journal of Clinical Endocrinology and Metabolism 200085 1206-1210. (https:// doi.org/10.1210/jcem.85.3.6453)

10 Sarlis NJ, Weil SJ \& Nelson LM. Administration of metformin to a diabetic woman with extreme hyperandrogenemia of nontumoral origin: management of infertility and prevention of inadvertent 
masculinization of a female fetus. Journal of Clinical Endocrinology and Metabolism 199984 1510-1512. (https://doi.org/10.1210/ jcem.84.5.5673)

11 Sir-Petermann T, Maliqueo M, Angel B, Lara HE, Perez-Bravo F \& Recabarren SE. Maternal serum androgens in pregnant women with polycystic ovarian syndrome: possible implications in prenatal androgenization. Human Reproduction 200217 2573-2579. (https:// doi.org/10.1093/humrep/17.10.2573)

12 Rosner W, Auchus RJ, Azziz R, Sluss PM \& Raff H. Position statement: utility, limitations, and pitfalls in measuring testosterone: an Endocrine Society position statement. Journal of Clinical Endocrinology and Metabolism 200792 405-413. (https://doi.org/10.1210/jc.20061864)

13 Vermeulen A, Verdonck L \& Kaufman JM. A critical evaluation of simple methods for the estimation of free testosterone in serum. Journal of Clinical Endocrinology and Metabolism 199984 3666-3672. (https://doi.org/10.1210/jcem.84.10.6079)

14 Rosner W. An extraordinarily inaccurate assay for free testosterone is still with us. Journal of Clinical Endocrinology and Metabolism 200186 2903. (https://doi.org/10.1210/jcem.86.6.7643)

15 Dunn JF, Nisula BC \& Rodbard D. Transport of steroid hormones: binding of 21 endogenous steroids to both testosterone-binding globulin and corticosteroid-binding globulin in human plasma. Journal of Clinical Endocrinology and Metabolism 1981 53 58-68. (https://doi.org/10.1210/jcem-53-1-58)

16 Hong H, Branham WS, Ng HW, Moland CL, Dial SL, Fang H, Perkins R, Sheehan D \& Tong W. Human sex hormone-binding globulin binding affinities of 125 structurally diverse chemicals and comparison with their binding to androgen receptor, estrogen receptor, and alpha-fetoprotein. Toxicological Sciences 2015143 333-348. (https://doi.org/10.1093/toxsci/kfu231)

17 Grasa MDM, Gulfo J, Camps N, Alcala R, Monserrat L, MorenoNavarrete JM, Ortega FJ, Esteve M, Remesar X, Fernández-López JA, et al. Modulation of SHBG binding to testosterone and estradiol by sex and morbid obesity. European Journal of Endocrinology 2017176 393-404. (https://doi.org/10.1530/EJE-16-0834)

18 Grishkovskaya I, Avvakumov GV, Sklenar G, Dales D, Hammond GL \& Muller YA. Crystal structure of human sex hormone-binding globulin: steroid transport by a laminin G-like domain. EMBO Journal 200019 504-512. (https://doi.org/10.1093/emboj/19.4.504)

19 Sodergard R, Backstrom T, Shanbhag V \& Carstensen H. Calculation of free and bound fractions of testosterone and estradiol-17 beta to human plasma proteins at body temperature. Journal of Steroid Biochemistry 198216 801-810. (https://doi.org/10.1016/00224731(82)90038-3)

20 Maher JE, Goldenberg RL, Tamura T, Cliver SP, Hoffman HJ, Davis RO \& Boots L. Albumin levels in pregnancy: a hypothesis decreased levels of albumin are related to increased levels of alphafetoprotein. Early Human Development 199334 209-215. (https://doi. org/10.1016/0378-3782(93)90178-W)

21 Ross HA, Meuleman EJ \& Sweep FC. A simple method for estimating equilibrium constants for serum testosterone binding resulting in an optimal free testosterone index for use in elderly men. Clinical
Chemistry and Laboratory Medicine 200543 613-616. (https://doi org/10.1515/CCLM.2005.106)

22 International Federation of Clinical Chemistry, Laboratory Medicine Working Group for Standardization of Thyroid Function Tests, Van Houcke SK, Van Uytfanghe K, Shimizu E, Tani W, Umemoto M \& Thienpont LM. IFCC international conventional reference procedure for the measurement of free thyroxine in serum: International Federation of Clinical Chemistry and Laboratory Medicine (IFCC) Working Group for Standardization of Thyroid Function Tests (WG-STFT). Clinical Chemistry and Laboratory Medicine 201149 1275-1281. (https://doi.org/10.1515/CCLM.2011.639)

23 Swinkels LM, Ross HA \& Benraad TJ. A symmetric dialysis method for the determination of free testosterone in human plasma. Clinica Chimica Acta 1987165 341-349. (https://doi.org/10.1016/0009. 8981(87)90179-3)

24 Van Uytfanghe K, Stöckl D, Kaufman JM, Fiers T, Ross HA, De Leenheer AP \& Thienpont LM. Evaluation of a candidate reference measurement procedure for serum free testosterone based on ultrafiltration and isotope dilution-gas chromatography-mass spectrometry. Clinical Chemistry 200450 2101-2110. (https://doi. org/10.1373/clinchem.2004.037358)

25 Ter Horst R, Jaeger M, Smeekens SP, Oosting M, Swertz MA, Li Y, Kumar V, Diavatopoulos DA, Jansen AFM, Lemmers H, et al. Host and environmental factors influencing individual human cytokine responses. Cell 2016167 1111.e13-1124.e13. (https://doi. org/10.1016/j.cell.2016.10.018)

26 Seong WJ, Chong GO, Hong DG, Lee TH, Lee YS, Cho YL, Chun SS \& Park IS. Clinical significance of serum albumin level in pregnancy-related hypertension. Journal of Obstetrics and Gynaecology Research 201036 1165-1173. (https://doi.org/10.1111/j.14470756.2010.01296.x)

27 Bui HN, Sluss PM, Hayes FJ, Blincko S, Knol DL, Blankenstein MA \& Heijboer AC. Testosterone, free testosterone, and free androgen index in women: reference intervals, biological variation, and diagnostic value in polycystic ovary syndrome. Clinica Chimica Acta 2015450 227-232. (https://doi.org/10.1016/j.cca.2015.08.019)

28 Damgaard-Olesen A, Johannsen TH, Holmboe SA, Soeborg T, Petersen JH, Andersson A, Aadhahl M, Linneberg A \& Juul A. Reference ranges of 17-hydroxyprogesterone, DHEA, DHEAS, androstenedione, total and free testosterone determined by TurboFlow-LC-MS/MS and associations to health markers in 304 men. Clinica Chimica Acta 2016 454 82-88. (https://doi.org/10.1016/j.cca.2015.12.042)

29 Rhea JM, French D \& Molinaro RJ. Direct total and free testosterone measurement by liquid chromatography tandem mass spectrometry across two different platforms. Clinical Biochemistry 201346 656-664. (https://doi.org/10.1016/j.clinbiochem.2013.01.005)

30 Zirkin BR \& Tenover JL. Aging and declining testosterone: past, present, and hopes for the future. Journal of Andrology 201233 1111-1118. (https://doi.org/10.2164/jandrol.112.017160)

31 Sielert L, Liu C, Nagarathinam R \& Craig LB. Androgen-producing steroid cell ovarian tumor in a young woman and subsequent spontaneous pregnancy. Journal of Assisted Reproduction and Genetics 201330 1157-1160. (https://doi.org/10.1007/s10815-013-0051-9)

Received in final form 19 April 2019

Accepted 29 April 2019

Accepted Preprint published online 29 April 2019 https://ec.bioscientifica.com https://doi.org/10.1530/EC-19-0110 (c) 2019 The authors Published by Bioscientifica Ltd

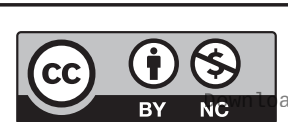

This work is licensed under a Creative Commons Attribution-NonCommercial 4.0 International License. ded from Bioscientifica.com at 04/26/2023 12:51:27PM 